\title{
Aristotle and the ERA: Measuring the immeasurable
}

\begin{abstract}
The research assessment framework is an unstable reality in many countries. While few would disagree that there is a need to measure and reward research excellence, there has been little investigation of how assessment mechanisms relate to knowledge itself. With a focus on the arts and humanities and writing from an Australian perspective, this paper draws together discussions of research assessment frameworks and forms of knowledge to consider what can and cannot be measured, and what we might gain from (or lose from not) measuring these things. We argue that the focus on measurable outputs risks a culture that favours effective packages of knowledge at the same time as ignoring the immeasurable, or hidden elements of research and scholarship - elements that Aristotle considered to underpin scholarship itself.
\end{abstract}

Key words: research assessment, arts and humanities, higher education

\section{Introduction}

The national Excellence for Research in Australia (ERA) initiative was announced in 2008 and is one of a growing number of national research assessment frameworks including those implemented in the UK (1986), Hong Kong (1993), Germany (1997), the Netherlands (2002), New Zealand (2003) and France (2005). The new Research Excellence Framework (REF) in the UK will be implemented in 2014 and retains the assessment foci of research output, impact and significance, and research environment (Higher Education Funding Council for England 2009). 
The ERA was flagged as a comprehensive research quality and evaluation system on the basis of evidence from other frameworks, which were heralded as having demonstrated that "research assessment improves research quality” (Sheil 2010, n. p). The Australian Research Council (ARC) viewed the UK Research Assessment Exercise (RAE), for example, as having increased international recognition of UK research, research funding and government funding, and both research quality and quantity. Conversely, academic research on the RAE has reported its less positive impact on academic work and identity (Harley 2002); motivation (Sikes 2006); publishing behaviour (Trevorrow \& Volmer 2012); scholarly autonomy (Weyer 2012); and interdisciplinary research (Rafols et al., 2012).

The ERA framework, which was implemented in 2010, classifies knowledge into three hierarchical levels comprising 22 divisions, 157 groups and 1,238 fields of research. Each of these classifications belongs to one of eight clusters. The arts and the humanities belong to a cluster called Humanities and Creative Arts (HCA). For each assessment, Australian universities submit information about their research activities to the ARC. This information includes staffing profile, publications and other research outputs (including creative research), awards, grants, income, and applied measures such as patents.

A Research Evaluation Committee (REC) for each discipline cluster comprises researchers with both discipline expertise and expertise in research evaluation. For each institution that has reached the necessary research volume threshold, the relevant REC rates the research excellence for each field of research (FoR) code within their discipline cluster. The thresholds for ERA 2012 were 50 indexed journal articles for disciplines where citation analysis is used, and 50 weighted research outputs for disciplines where peer review is used. A range of summary indicators and quality assessments provided by the ARC includes measures of research application and 
recognition, as well as more traditional measures of quality such as citation analysis or peer review. There are also discipline-specific national and international benchmarks, again provided by the ARC. In cases where the REC does not have the relevant expertise to assess a specific body of work, additional peer reviewers assess the research outputs. In 2012, over 1,000 researchers were involved as members of a REC or as peer reviewers.

The REC assigns a rating at the four-digit FoR code level unless the volume threshold is not reached, in which case the two-digit FoR code is assessed. ERA utilises a five-point rating scale in which the Unit of Evaluation profile is characterised by evidence of performance as described in Table 1 .

\section{Table 1: Rating of performance applied to each Unit of Evaluation}

\section{Rating Description of performance for each rating}

$5 \quad$ Evidence of outstanding performance well above world standard

$4 \quad$ Evidence of performance above world standard

3 Evidence of average performance at world standard

2 Evidence of performance below world standard

1 Evidence of performance well below world standard

(Commonwealth of Australia 2012)

The stated objectives of the ERA are to establish an evaluation framework; to provide a national stocktake of research to identify research strengths and opportunities; to identify excellence in research; to identify emerging areas; and to benchmark research nationally and internationally. Writing from the perspective of the arts and humanities, this paper focuses on the third of these points: identifying excellence in research.

While few would disagree with the need to recognise and reward research excellence, there has been little investigation of how assessment mechanisms relate to knowledge itself. In this paper we explore what can and cannot be measured, and what 
we might gain from (or lose from not) measuring these things. We establish the context with a brief description of recent change experienced within Australian higher education, and some of the ways in which knowledge has been categorised. We then step back in time to the emergence of the humanities, considering the treatment of knowledge long before the era of the corporatised university. We conclude by highlighting a number of challenges, benefits and implications presented by the implementation of research assessment frameworks, not least of which is the extent to which they can assess research.

\section{The Australian context of assessment}

The ERA framework is an inevitable result of rapid change within Australia's higher education sector over the past forty years, with major shifts largely aimed at increasing productivity to meet national goals for higher education learning and research. Over the same period, reduced government funding forced higher education institutions to earn income elsewhere. In 1996, for example, Australian state and federal governments provided approximately 58\% of all funds to universities. By 2005 government funding was reduced to $40 \%$ (Universities Australia 2009) and it is likely that this trend will continue.

The growing need for sourcing non-government income explains in part the institutional focus on income generated through research and high income-producing courses; however, the focus is also indicative of a cultural shift. Recent history reveals a culture of corporatisation, amalgamation and increasing accountability within a climate of diminishing funding and the corresponding need to demonstrate that existing monies are spent productively and efficiently (Meyers 2012; Parker, 2005). This is unsurprising given the size of the sector: Australia's 39 universities alone enrol more than one million students and employ more than 100,000 staff (Universities Australia 
2012). The measurement of excellence is central to the future of Australian higher education, since excellence-however it is defined and measured-equals funding.

\section{Assessing knowledge through assessment frameworks}

Within this setting the treatment of knowledge is crucial, because divisions of knowledge and the reporting of achievement against them have considerable implications for academics and managers within an environment characterised by increased accountability and decreased employment stability, fierce competition for competitive funding, and concern about both individual research track record and publicly-displayed institutional achievement.

We draw here a distinction between a number of words in English that relate to knowledge or its use: for example, information, insight, wisdom, intelligence, and critical thinking. Within the higher education sector, knowledge is (perhaps implicitly) understood in all these nuances. Whilst knowledge presented in the form of a scientific treatise or creative production probably includes aspects of information, wisdom and intelligence, most importantly it demonstrates insight and critical thinking, a point with which no doubt Aristotle would agree. In Nicomachean Ethics (Nic. Eth.), Aristotle deals with actions done and the rational quality inherent in them, listing five qualities through which the mind can find the truth either by affirming or denying: art or technical skill, scientific knowledge, prudence, wisdom, and intelligence (Bekker, 1934, 1139b). Aristotle adopted four Questions of Cause, with 'cause' referring to an explanatory factor or aition (ailtıv) that assists in the generation of knowledge. In simple terms the formal cause asks what sort of thing it is; the material cause asks about a thing's substance; the efficient cause asks how it came into being; and the final cause asks about its role. 
Frederick (1998, p. 1) explains that Aristotle "formalized the relation between the evidence gathered by studying things in the world and coming to true conclusions about those things", emphasising method and logic in the process of research through which knowledge is generated. As Mulcahy (2010, p. 307) explains,

Aristotle used the term 'liberal' to refer to the knowledge one seeks out of mere curiosity or for enjoyment, and he characterized knowledge that was sought for some purpose beyond itself as mechanical or useful (1903, p. 108). This laid the groundwork for a distinction between liberal knowledge or liberal education intended to promote one's potential to learn and to enjoy knowledge, and professional or practical education intended to offer knowledge and skills needed in professional areas such as the practice of law, in a range of vocational and technical occupations, and in service to others.

The simplistic treatment of knowledge within assessment frameworks such as the ERA does not consider the method and logic in the process of research; nor does it value insight and critical thinking. However, the categorisation of fields of study is far from new.

\section{The (new) humanities.}

Taking our starting point from Aristotle, we step back in time to consider the emergence of what we know as the humanities. We then explore how knowledge has been understood in this multidisciplinary field.

The ability to know has been of interest since ancient times, and formal divisions of knowledge can be traced back to the ancient world. Aristotle, who wrote on an array of subjects ranging from physics to poetry, is remembered not as a specialist but as a philosopher. This is because philosophy, in Aristotle's time, was taken to mean the broad pursuit of wisdom or knowledge by intellectual means. However, for Aristotle and his contemporaries, scholarly disciplines were determined 
in response to the research question being asked and the method employed to ask the question. There is a long tradition of categorising what we might call 'the liberal arts', from the Stoics' grouping together of grammar, rhetoric and dialectics, through the acknowledgment of this trivium in the European Middle Ages over and against the remaining four liberal arts—arithmetic, geometry, astronomy and music —as a quadrivium of mathematical subjects. These divisions were made on the basis that "the trivium includes those aspects of the liberal arts that pertain to mind, and the quadrivium, those aspects of the liberal arts that pertain to matter” (Joseph 2002, p. 3). Thus as the humanities disciplines emerged in the Renaissance period as educational programs in response to humanism and the revival of Graeco-Roman culture, their focus was the mind, with subjects studied and analysed rather than acted out or experienced (Levi 1970).

Despite the widespread impetus of the humanist movement, the humanities did not emerge as distinct fields of study until the nineteenth century, and it was only then that the term 'humanities' came into common use. Shumway (2007, p. 1) suggests that the modern humanities disciplines are the result of three conditions: "a shift in the conception of knowledge that demoted texts to objects of study; the break up of philosophy into the sciences; and the invention of the disciplinary form itself [entailing among other things] new pedagogical spaces of the classroom and the laboratory, and new practices, such as the seminar”.

The cluster of subjects we now recognise as 'traditional' humanities were thus largely defined in the 19th century. Aligned with humanist fascination with the ancient world, many of the humanities centred on studies of antiquity: classical history, language, arts, culture, philosophy and so on. Modern languages and literature came later, and in many countries the creative arts moved to specialist institutions only to be brought back into the university system over the past 50 years or so. Contemporary and 
popular culture count among the subjects to have been added over that period. As Tymoczko (2001, p. 287) explains,

[C]hanging views of knowledge during the 20th century undermined the 19th-century epistemological and ideological premises of the traditional humanities and, indeed, of academe as a whole. The humanities were by and large transformed, particularly in the second half of the 20th century, as post-positivist views of knowledge shifted inquiry away from primary research oriented toward digging out and amassing observable 'facts', to self-reflexive methods involving interrogations of perspective, premises, and the framework of inquiry itself.

For the vast majority of academics, knowledge and its application is a matter for the mind. The advent of creative production into the mainstream of acceptable academic outputs brings a further possibility that perhaps knowledge may be linked with the physical knowing within the body or even to some idea of spirit, whether this is related to a reality beyond the human or regarded as an aspect of the human.

Neither of these ideas would be strange to pre-enlightenment societies. The first of Aristotle's qualities through which the mind can find the truth is art or technical skill. In Aristotle's time, art was not defined in terms of the creative arts. Architectural skill, for example, was defined as an art:

Now architectural skill, for instance, is an art, and it is also a rational quality concerned with making; nor is there any art which is not a rational quality concerned with making, nor any such quality which is not an art. It follows that an art is the same thing as a rational quality, concerned with making, that reasons truly... (Bekker, 1934, 1140a)

On this basis it may have been easier to accommodate the arts within a 300BCE research framework than in a contemporary one.

Humanities is and has always been interested in what and how humans know and create and have insight in relation to themselves and other realities, imagined entities or living beings. Perhaps what is 'new' in the new humanities is greater 
acknowledgement of the entire action of knowledge production and application to include creative activity or professional application.

Wierzbicka (2011) writes that the word 'humanities' is misunderstood because it is not commonly used. Her concerns are borne out in the different definitions adopted by each of the 56 State Humanities Councils in the United States, which define the Humanities in terms of activities within their region. Likewise there is little consistency between universities, which define humanities according to the courses they offer. Bennett (2011) notes that Stanford University, which has fifteen humanities departments, describes the humanities as "the study of the myriad ways in which people, from every period of history and from every corner of the globe, process and document the human experience” (Stanford 2010, n. p). In contrast, Princeton (2011, n. p) adopts a common, non-vocational definition of the humanities: namely "studies intended to provide general knowledge and intellectual skills (rather than occupational or professional skills).”

Non-vocational definitions such as the one Princeton uses have formed the basis of many statements in defence of the humanities, which some believe "can defend themselves best by refusing to make any claims of utility” (Fish, 2008, n. p). However, this is a perilous stance that has failed to stem criticism that traditional humanities programs are "both expensive and relatively useless" (Humanities in the United States 2010) in the job market. Such claims have contributed to the demise of many traditional humanities courses. In Australia, for example, Queensland University of Technology closed its School of Humanities and Human Services in favour of a focus on the more popular (and vocationally oriented) creative industries (Ianziti May 2007, n. p). The need for clarification and rigorous debate is further illustrated with the example of the Australian Academy of the Humanities (AAH), which received research funding "to chart the disposition and trends of the humanities sector in 
Australia ... to arrive at a nuanced understanding of the key issues facing the sector today” (AAH 2009, n. p).

Whilst not the primary focus of this paper, the treatment of non-traditional forms of research output such as artistic or creative research needs special mention. Following a decade during which artistic research was not formally recognised within Australian higher education, the ERA brought recognition for artistic research in four categories: Original (creative) works in the public domain; Live performance works in the public domain; Recorded (performance) public works; and Curated or produced substantial public exhibitions, events or renderings (Australian Research Council 2008).

These 'non-traditional' research outputs are subject to peer review, and each output nominated for peer review must be accompanied by a 250 -word statement that identifies the research background (field, context and research question), the research contribution (innovation and contribution to new knowledge), and the research significance (evidence of excellence). The requirement for a research statement is at odds with the peer recognition that legitimises research in most other areas, and the peer assessment process raises questions about public recognition and quality, and about transparency and consistency. As Blom, Bennett and Wright (2011, p. 364) argue,

An original contribution to knowledge can be judged by those with experience in the discipline - one's peers. However, artistic research is more than that and there is a compelling argument that, rather than being merely an equivalent, it should be recognized as research in its own right.

Aside from the necessity to demonstrate 'equivalence' with traditional outputs, accumulating the evidence required for the assessment of artistic research can be complex and demanding, both of individuals and institutions (Schilo 2012). Writing 
from the UK, Niedderer and Roworth-Stokes (2007, p. 5) have identified another potentially negative impact of recognising a previously unrewarded activity: namely that "by opening research to the inclusion of [artistic] practice, the need arose to legitimise the use of practice within research and with regard to its contribution to knowledge." Contrary to Aristotle's notion of art dealing with the same objects as chance, research assessment requires academics to unravel hidden, at times spontaneous components of their work that can be considered to be at risk if subjected to over-analysis.

\section{Are we attempting to measure the immeasurable?}

Universities are supported by public money and have a duty to demonstrate the efficient and effective use of those monies. Whilst TEQSA is evaluating higher education institutions against standards, ERA is seeking to differentiate between them in terms of quality and excellence. That said, could any framework accurately reflect excellence in research? Should we accept the need to measure research? Given the cost of such an assessment exercise, would the funding be better spent on research itself? What influence is ERA having on the academics whose work is assessed? To begin to answer these questions we highlight below a number of challenges, benefits and implications presented by the adoption of research frameworks. In so doing we hope to stimulate further debate about the merits and disadvantages of research measurement, and perhaps prompt further discussion about how this process can be managed within an institution.

\section{Traditional scientific research remains the norm, but can one size fit all?}

The first issue we address is that traditionally notated 'scientific' research remains the accepted norm. This has particular implications for the arts and humanities, where 
innovative and non-traditional modes of research need to be accommodated within much less flexible research frameworks. However, the sciences are similarly concerned about the integrity and efficacy of research frameworks.

Speaking at a 2004 Australian national conference on measuring research excellence, Jim Peacock, then President of the Australian Academy of Science, described the changing nature of science research and research training, which features increasing intersections across disciplines. Describing the changing definition of science in the UK, Peacock (2004, p. 6) explained the confusion that arose when policy makers "quite explicitly, up front, talk about science, engineering, social science and the humanities ... [W]hen they talk about science skills and innovation they are talking about the whole spectrum". The emergence of broad research areas such as sustainability lends support to the notion that the traditional 'silos' of activity are less and less relevant to contemporary research. Moreover, as Marginson (2010, p. 4) has argued, performance assessment and output modelling have meant that: "Larger aggregated outcomes, such as the contribution of liberal education to citizen formation, or the long term effects of basic research, fall out of the picture”. Short reporting cycles also lead to the question of how a retrospective measure can accommodate the new as well as the extant. This includes new fields of study, new knowledge on the edge of a subject area, and new researchers.

The relative inability of research frameworks to accommodate multidisciplinary and inter-disciplinary research is troublesome, since in reality many more academics are working across traditional boundaries and it is this intersection that offers some of the most exciting opportunities in contemporary research. However, in several studies the problem of accommodating interdisciplinary work has been traced beyond the general framework to those engaged especially in peer review within that framework. As Rafols et al (2012, p. 1262) note, the possible bias of peer reviewers 
against interdisciplinary work was identified as problematical as early as the Boden Report, which warned of "systematic bias" (ABRC 1990, p. 4). This must be of especial concern then for the humanities, where peer review is the norm for the ERA.

\section{Does ERA measure knowledge?}

Perhaps, if we recognised how knowledge has come about and if the methods of measuring were applied in the right way, or in a way that takes account of all the aspects that have been required to produce a certain output, we could measure knowledge and its application. The very thought of implementing such a complex and expensive measure would represent a formidable task for any administrator or researcher.

While some forms of the application of knowledge are clear in learned journal articles, the process of generating this knowledge may be unclear. Does this output simply comprise the amassing of information? Was critical thinking brought to bear on the issue or gathered material? Was there a moment of insight, a sudden clarity, a leap from 'the facts' to some idea, and no explanation for how the leap occurred? Did numerous previous attempts, experiments and perspectives inform this insight? What was the state of mind or body of the academic who produced such a work?

In a sense, where knowledge appears easiest to understand and evaluate it may be the least understandable. The evaluation of a creative work, for example, may be difficult for many academics to understand. A creative work can at least superficially appear more transparent in its various aspects: aspects such as mind, body, critical thinking and insight. However, as Elliot (2011, p. 104) asserts:

We may readily agree that a dance is not a painting, but the varieties of measuring criteria that derive from this obvious observation are manifold ... the ERA process has focused the notion 
of measurement on the creative arts and it is up to creative practicing academics to articulate the standards and defend the validity of the way 'creatives' also create new knowledge.

This articulation could include consideration of the less daunting and perhaps more practical question of what we are currently missing: what is there of value that cannot or has not been measured?

\section{Does context matter?}

Is research behaviour sensitive to context? How does the measure of research take into account the context of the research or researchers or the broader context of the institution within which the research takes place, or indeed the context of the national and international research beyond any single institution? While the initial contribution may be considered academic, a brief consideration of hermeneutics can illustrate that there are always social, cultural, and political values inherent in particular ways of producing or applying knowledge.

Ways of knowing and interpreting the world are based in multiple integrated beings, objects and methodologies: knowing facts, knowing oneself and knowing others in attempting to know facts; acknowledging that where one stands and who one is can make a difference to the way one asks a question, or even what questions one chooses to ask in order to know something. Questions and standpoints inevitably present a particular line of sight, or view, so the contextualisation of the activity in which knowledge is produced or applied may be important. Again, the multiplicity of contexts may be so great as to make reasonable measurement and comparison of activity too difficult, and yet it remains crucial.

Scientists have long acknowledged that their production or application of knowledge is not limited to the activity of the rational, neutral or disinterested mind; 
and yet what lies beyond the limits of the rational is not acknowledged in the process of measuring the knowledge output. Whether in physics or painting, the ERA process rewards the ability to package research into a measurable output such as a traditional journal article, or to defend it in the form of the research statement accompanying a creative work. This has led to a culture of hiring writers - effective communicators of knowledge - to finesse both academic papers and grant applications, and of course to package and massage institutional ERA submissions. Whilst effective packaging may be a legitimate element of communicating knowledge, it is not knowledge.

ERA, then, does not reward the 'knowing' per se. Rather, it rewards the expression of knowledge in an acceptable, measureable way. What are the implications of this? At first sight, the 1,238 different specialist fields of research within the ERA Framework appear far from restrictive, recognising engagement across multiple academic fields of research and a breadth of disciplinary knowledge and expertise. However, the divisions also present potential silos of activity against which achievement is reported by institutions. Within institutions, high-scoring fields of research are likely to attract additional strategic funding whilst low-scoring areas are likely to receive either remedial attention or the threat of closure: "Given the rumoured imperatives in most universities in the country to either 'bolster or bury' research outputs to ensure a quality submission, the strategic implications for particular disciplinary groupings at a four-digit level are of concern (Schilo 2012, p. 222). Accordingly, academics feel increasing pressure to publish within their disciplines and contribute to their area's research performance, and they face increasing resistance to multidisciplinary research. This is of course common to multiple frameworks: the REF in the UK has also been said to "mitigate against most cross-disciplinary and multidisciplinary work. For those engaged in the study of subjects that lack a clear 
disciplinary 'home', such as sustainability, this retreat is particularly frustrating” (Wells 2011, p. 4).

In sum, the commodification of knowledge is problematic for governments because knowledge per se has no common currency, can be tacit or hidden, and can be presented in multiple ways. In simple terms, a published research output will often report the results or outcomes of knowledge, rather than knowledge itself. Knowledge is not something research assessment frameworks can measure.

\section{Does ERA measure excellence?}

The ERA seeks to "identify excellence across the full spectrum of research performance” (ARC 2011a, n. p). Units of Evaluation are assessed and rated by Research Evaluation Committees comprised of experienced, internationally recognised experts. Research quality, or excellence, is assessed "on the basis of publishing behaviour, citation analysis, ERA peer review, and peer reviewed Australian and international research income” (ARC, 2011b, p. 9). The ERA initially ranked research journals, implying that articles published in highly ranked journals are better than those published elsewhere (Vanclay 2010). The journal rankings were officially abandoned in 2011, but they continue to impact scholarly publishing activity.

Returning once more to context and value, a further consideration is the potential loss of the independent scholarly voice (Parker 2005) as academics become more risk-adverse in their research and publishing decisions. Whilst ERA is almost unique in that it does not report individual performance, institutions are closely monitoring individual performance and are drawing on the ERA data to do so. This adds to the pressure to align valuable research time with activity that is immediately publishable, and the dilemma was not unforeseen. Writing a decade ago, Brew (2001, p. 86) was one of several commentators to warn that "the application of a rational 
framework to research activity does away only with those social values which differ from the dominant values in the academic community"; and in the UK the particular threat to research in the arts and humanities was met with the comment that the REF "may have the effect of disincentivising research that does not translate into immediate measurable impact for public policy or industry in the UK” (Shepherd 2009, n. p). There exist numerous examples of research projects being refined to align with the scope of a targeted journal or funding scheme; in general "most faculty have engaged in, if not exactly bought into, the models of assessment and evaluation that often link academic performance and centrality to financial salience, all in the name of value” (Delgado 2011, p. 1809).

Graham (2004) raised concerns about a reliance on the imperfect measures of grant success and citations, explaining that large grants with large teams and expensive equipment are historically less successful than individuals or small teams; and that citations do not work as a measure, neither in the short term nor the longer term. Indeed, citations within a research framework reporting cycle are unable to give, even in the sciences, an accurate view of research excellence. Citing the example of a seminal paper, the findings of which influence clinicians' daily practice, Graham (2004, p. 13) remarked that the paper itself would be rarely cited today. The research "is something that we use all the time and is of enormous, immense importance to us in treating patients, but its discovery is now something that has been forgotten.”

We seem to have come full circle, back to the context of research. The simplistic, purely quantitative approach to research assessment has long been accused of "rewarding mediocrity rather than quality" (McCalman 2004, p. 22), and there are ample examples of why this is so. Wells (2011, p. 2) agrees that "it is perfectly possible for a research project to be a complete disaster for the funding body, it could fail to deliver what was required, it could be terribly managed, and yet it could be 
regarded as excellent if journal publications of a sufficient quality result”. Similarly, it is quite feasible in the current system to ignore the larger context of academic work in order to enhance one’s chances of success (Marginson 2011).

As institutions strive to achieve in the league tables and research assessment "becomes the driver of teaching policies, including course offerings and class sizes, as well as institutional and individual choices regarding topic, type of research and publication destination” (Thornton 2008, p. 7), it threatens to essentially relegate scholarship, teaching and public activity to the backbench.

\section{Closing comments}

Scholars in the arts and humanities analyse both the subject of their research and the relationships of that subject with the external environment, considering aspects such as purpose, reception, use and impact. In essence, these researchers rarely analyse something without looking beyond it; yet looking beyond it invariably entails working across disciplinary boundaries. For Australian researchers this might seem the antithesis of the ERA with its 1,238 fields of research.

Aristotle asserted that we do not understand something until we know what it is for, what it is made from, what it does, how it interacts, and who needs it. Frederick (1998, p. 2) describes this assertion as problematic "in the sense that sometimes, innovations happen by accident thus not allowing us to fully know what it is for, what it aims at or what is does." However, Aristotle could appreciate the failures and accidental discoveries, and truly embodied research journeys as underpinning future thinking, future Forms or universals. The issue here is how much of Aristotle's thinking would have been measurable within a research framework such as the ERA. His broad subject base would certainly not be well received, and yet the ability to transcend boundaries is perhaps what most defines making and managing knowledge 
in the arts and humanities. Having selected his field of research codes and considered what his school, faculty and institutional priorities were, it is entirely possible that Aristotle would have needed to reconsider his research activities in order to be deemed research active.

Broadly speaking, research assessment has so far fallen into four categories: peer review, self-assessment, historical rankings, and quantitative measures. The latter is increasingly common as the complexities of other approaches come to the fore. Thus the peer review process for many areas of the arts and humanities is more likely to be both presented and treated by research administrators/managers as problematical rather than as an equal partner with the quantitative measure so easily applied to the sciences.

Whilst it is natural to categorise and order things to understand them better, the divisions or categories imposed by research assessment frameworks serve the very different purpose of responding to a broad policy agenda. Current measures do not measure research or excellence; rather, they reward outputs of research that have been packaged in a measurable way. An unintended but inevitable result is that academic behaviour is skewed.

We began by suggesting that few would disagree that there is a need to recognise and reward research excellence. We hold to this view, but question whether anyone has yet in fact found a way to do this. Hunt observed in 1959 that research is "not an end in itself, but a means to the primary ends of scholarship: teaching and public activity” (in McManners \& Crawford 1965). Aristotle would have agreed to some extent:

It is true that a certain variety is to be observed among the ends at which the arts and sciences aim: in some cases the activity of practising the art is itself the end, whereas in others the end is some product over and above the mere exercise of the art; and in 
the arts whose ends are certain things beside the practice of the arts themselves, these products are essentially superior in value to the activities. But as there are numerous pursuits and arts and sciences, it follows that their ends are correspondingly numerous: for instance, the end of the science of medicine is health, that of the art of shipbuilding a vessel, that of strategy victory, that of domestic economy wealth (Bekker, 1934, 1094a).

Ultimately Aristotle sees two possible outcomes or ends for the arts and sciences: first, the knowledge of the truth which comes from the activity of practising the art itself; and secondly, the public product that results from the activity and which is superior to the activity. The ERA represents an attempt to measure the first, but it can be plotted as a kind of mid-point between these two ends; it measures not the activity but rather the package that describes or attempts to communicate the activity, and nor does it measure the public impact or product. Future research assessment exercises need to move back from the mid-point and consider how to assess effectively the activity of research, and to consider measuring the superior end that is the public impact or product that results.

\section{References}

Advisory Board for the Research Councils. (1990) Peer review: A Report to the Advisory Board for the Research Councils from the Working Group on Peer Review. London: ABRC.

Aristotle. (1903) in Burnet, J. (ed.) Aristotle on Education. Cambridge: Cambridge University Press. 
Australian Academy of the Humanities. (2009) The humanities in Australia today.

Retrieved: December 10, 2010, from

http://www.humanities.org.au/Policy/HumanitiesToday.html.

Australian Research Council. (2008) ERA indicator descriptors. Available at:

http://www.arc.gov.au/pdf/ERA_Indicator_Descriptors.pdf (accessed 1 May 2010)

Australian Research Council. (2011a) Excellence in Research for Australia (ERA).

Available at:

http://www.arc.gov.au/pdf/era12/ERA\%20Factsheet_Jan\%202012_1.pdf

(accessed 16 May 2012)

Australian Research Council. (2011b) ERA 2012 submission guidelines. Available at: http://www.arc.gov.au/pdf/era12/ERA2012_SubmissionGuidelines.pdf (accessed 17 May 2012)

Bekker, A. I. (1934) Aristotle in 23 Volumes, Translated by H. Rackham, Harvard University Press, Cambridge, MA.

Bennett, D. (2011) 'Making and managing knowledge in the 'new' humanities: An Australian experience', International Journal of the Humanities, vol. 9, no. 1, pp. 236-244.

Blom, D., Wright, D. \& Bennett, D. (2011) 'How artists working in academia view artistic practice as research: Implications for tertiary music education', International Journal of Music Education, vol. 29, no. 4, pp. 359-373.

Brew, A. 2001, The nature of research, Routledge/Falmer, London.

Commonwealth of Australia (2012) ERA 2012 evaluation handbook, Commonwealth of Australia, Canberra.

Delgado, F. (2011) 'Reflecting on academic labor from the other side’, International Journal of Communication, vol. 5 2011, pp. 1808-1804. 
Elliot, R. (2011) 'Painting monkey or painting elephant?’ Australian Universities’ Review, vol. 53, no. 2, pp. 103-109.

Frederick, D. A. (1998) ‘The Aristotelian Framework for Innovation - Articulating, igniting and implementing an effective innovation framework', Social Science Research Network. Available at: http://dx.doi.org/10.2139/ssrn.1030825 (accessed 16 May 2012)

Graham, R. (2004) September, ‘Excellence in investigator-driven research’, in Measuring excellence in research and research training, proceedings of the National Academies Forum, Australian Academy of Science, Canberra, pp. 10 20.

Harley, S. (2002) 'The Impact of research selectivity on academic work and identity in UK universities', Studies in Higher Education, vol. 27, no. 2, pp. 187-205.

Higher Education Funding Council for England. (2009) Research Excellence Framework. Available at: http://www.hefce.ac.uk/research/ref (accessed 2 October)

Ianziti, G. (2007) May 10, ‘Traditional humanities out: Creative industries in’, [Blogpost]. Available at: http://www.onlineopinion.com.au/view.asp?article=5832 (accessed 12 June 2011)

Joseph, M. (2002) 'The trivium: The liberal arts of logic, grammar, and rhetoric,' edited by M. McGlinn, Paul Dry Books, Philadelphia.

Levi, A. W. (1970) The humanities today, Indiana University Press, Bloomington. McCalman, I. (2004) September, 'Excellence in the humanities, creative arts and media', in Measuring excellence in research and research training, proceedings of the National Academies Forum, Australian Academy of Science, Canberra, pp. 20 - 26. 
McManners, J. \& Crawford, R. M. (1965) The future of the Humanities in the Australian Universities, occasional paper 8, 1965, Melbourne, Melbourne University Press on behalf of the Australian Humanities Research Council. Marginson, S. (2010) 'The limits of market reform in higher education', Higher

Education Forum, 7, March, pp. 1-19. Research Institute for Higher Education, Hiroshima University.

Marginson, S. (2011) ‘Higher education and public good’, Higher Education Quarterly, vol. 65, pp. 411-433.

Meyers, D. (2012) Australian universities: a portrait of decline, Brisbane, AUPOD. Mulcahy, D. G. (2010)

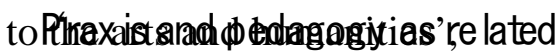
Arts and Humanities in Higher Education, vol. 9, no. 3, pp. 305-321. Available at: http://ahh.sagepub.com/content/9/3/305. (accessed December 10 2011)

Niedderer, K. \& Roworth-Stokes, S. (2007) 'The role and use of creative practice in research and its contribution to knowledge'. Unpublished paper presented at the International Association of Societies of Design Research. Hong Kong, Hong Kong Polytechnic University.

Parker, Jan (2005). 'Voice and Academic Identity in 'Changing Places', in Tight, M. (ed.) International relations. International perspectives in higher education research, vol. 3, no. 3. Oxford, UK, Elsevier, pp. 185-203.

Parker, L. (2005) 'Welcome to "the rough and tumble”: managing accounting research in a corporatised university world', Accounting, Auditing \& Accountability journal, vol. 18, no. 1, pp. 5-13.

Peacock, J. (2004) September, 'Excellence in the humanities, creative arts and media', in Measuring excellence in research and research training, proceedings of the National Academies Forum, Australian Academy of Science, Canberra, pp. 1 - 3. 
Princeton University. (2011) WordNet: A lexical database for English. Humanities. Available at: from http://wordnet.princeton.edu. (accessed 14 February 2011)

Rafols, B., Leydesdorff, L., O-Hare, A., Nightingale, P., \& Stirling, A. (2012). 'How journal rankings can suppress interdisciplinary research: a comparison between Innovation Studies and Business \& Management', Research Policy, vol. 41, no. 7, pp. 1262-1282. Retrieved February 10, 2013, from http://www.sciencedirect.com/science/article/pii/S0048733312000765.

Rosenberg, T. (2008) 'Worthy of Gordius: The knotty problem of configuring creative practice as research, or indeed research for creative practice', unpublished paper presented at On Artistic Research, ReykjaviÅLk, Icelandic Academy of the Arts. Schilo, A. (2012) 'Nobody will thank me for this: Championing the ERA', Continuum: Journal of Media \& Cultural Studies, vol. 26, no. 2, pp. 215-223.

Sheil, M. (2010) 'Research in the national interest: Enabling the future', unpublished presentation at Curtin University, Perth.

Shepherd, J. (2009) October 13, 'Humanities research threatened by demands for “economic impact”, The Guardian online. Available at: http://www.guardian.co.uk/education/2009/oct/13/research-funding-economicimpact-humanities (accessed 10 April 2012)

Shumway, D. R. (2007) 'What are the Humanities?’, Focus, vol. 36, no. 6, pp. 1, 6. Sikes, P. (2006) 'Working in a "new” university: in the shadow of the Research Assessment Exercise?' Studies in Higher Education, vol. 31, no. 5, pp. 555-568. Stanford University, 2011, What are the humanities? Retrieved: February 14, 2011, from http://humanexperience.stanford.edu/what.

Tertiary Education Quality and Standards Agency. (2012) About TEQSA. Available at: http://www.teqsa.gov.au (accessed 10 May 2012) 
Thornton, M. (2008) 'The retreat from the critical: Social science research in the corporatised university’, Australian Universities Review, vol. 50, no. 1, pp. 5-10.

Trevorrow, P., \& Volmer, D. A. (2012) 'Dispelling the myths surrounding the Research Excellence Framework’, Rapid Communications in Mass Spectrometry, vol. 26, pp. 399-402 (retrieved February 24, 2012, from doi: 10.1002/rcm.6133.

Tymoczko, M. (2001) 'Will the traditional humanities survive in the 21st century?' Organization, vol. 8, no. 2, pp. 285-297.

Universities Australia. (2012) Australia’s Universities. Available at: http://www.universitiesaustralia.edu.au/page/australia-s-universities/ (accessed 16 May 2012)

Universities Australia. (2009) University Overview. Available at: http://www.universitiesaustralia.edu.au/content.asp?page=/universities/overview. htm (accessed 11 August 2009)

Vanclay, J. K. (2011) ‘An evaluation of the Australian Research Council’s journal ranking', Journal of Informetrics, vol. 5, pp. 265-274.

Wells, P. (2011) 'The research excellence framework: And why it isn't', Comment and analysis, occasional paper for The Centre for Business Relationships, Accountability, Sustainability and Society. Available at: http://www.brass.cf.ac.uk/uploads/Research_Excellence_Framework290410.pdf (accessed 17 May 2012).

Weyer, E. (2010) 'Loosely organized to tightly managed? Evidence from the analysis of research evaluation processes in the UK and the Netherlands'. $28^{\text {th }}$ conference of the European Group for Organization Studies, July, Helsinki.

Wierzbicka, A. (2011) 'Defining “the humanities”', Culture and Psychology, vol. 17, no. 1, pp. 31-46 
Wikipedia. (2011) last modified December 2011, Humanities in the United States, 2010. Available at:

http://en.wikipedia.org/wiki/Humanities_in_the_United_States (accessed 6 February 2011) 